\title{
Automated Decision-Making and Environmental Impact Assessments: Decisions, Data Analysis and Predictions
}

\author{
Zoe Nay, Anna Huggins and Felicity Deane \\ Queensland University of Technology, Australia
}

\begin{abstract}
This article critically examines the opportunities and challenges that automated decision-making (ADM) poses for environmental impact assessments (EIAs) as a crucial aspect of environmental law. It argues that while fully or partially automating discretionary EIA decisions is legally and technically problematic, there is significant potential for data-driven decision-making tools to provide superior analysis and predictions to better inform EIA processes. Discretionary decision-making is desirable for EIA decisions given the inherent complexity associated with environmental regulation and the prediction of future impacts. This article demonstrates that current ADM tools cannot adequately replicate human discretionary processes for EIAs - even if there is human oversight and review of automated outputs. Instead of fully or partially automating EIA decisions, data-driven decision-making can be more appropriately deployed to enhance data analysis and predictions to optimise EIA decision-making processes. This latter type of ADM can augment decision-making processes without displacing the critical role of human discretion in weighing the complex environmental, social and economic considerations inherent in EIA determinations.
\end{abstract}

Keywords: Environmental impact assessments; automated decision making; discretionary decisions; data-driven decision making.

\section{Introduction}

Automated decision-making (ADM), in which automated processes are used to execute or inform decisions, ${ }^{1}$ is increasingly permeating public sector decision-making throughout the world. ${ }^{2}$ This phenomenon has been met with mixed responses, ranging from optimism about the potential for ADM to enhance the efficiency and accuracy of government decision-making processes, ${ }^{3}$ to deep concern about the risks that poorly designed ADM may pose to rule of law values ${ }^{4}$ and the legitimacy of government decisions. ${ }^{5}$ To date, however, comparatively little scholarly attention has been paid to ADM and environmental impact assessments (EIAs), an important subset of public sector decision-making. ${ }^{6}$ This article addresses this gap by critically examining the opportunities and challenges ADM poses for this high-volume and consequential decision-making domain. It

\footnotetext{
${ }^{1}$ Yeung, "Algorithmic Regulation: A Critical Interrogation," 507.

2 See, e.g., Zalnieriute, "The Rule of Law and Automation of Government Decision-Making," 3.

${ }^{3}$ See, e.g., Coglianese, "Regulating by Robot," 1147.

${ }^{4}$ See, e.g., Zalnieriute, "The Rule of Law and Automation of Government Decision-Making," 425.

${ }^{5}$ See, e.g., Citron "The Automated Administrative State," 21-22.

${ }^{6}$ To date, most analyses of the potential uses of ADM in environmental governance have focused on potential compliance and enforcement purposes: see, e.g., Glicksman, “Technological Innovation, Data Analytics and Environmental Enforcement," 64-77; Coglianese, "Deploying Machine Learning for a Sustainable Future," 3-6. The intersection between EIAs and new technologies, including the "deployment of highly automated digitised systems constituted through a combination of 3D printing, advanced industrial robotics, autonomous transport, Internet of Things, and Artificial Intelligence' remains largely unexplored: Dusík, "Strategic Environmental and Social Assessment of Automation," 4. Bice and Fischer question whether artificial and automated technologies make 'optimal decisions' in impact assessments, and if so, 'what role will human assessors play?': Bice, “Impact Assessment for the $21^{\text {st }}$ Century: What Future?” 91.
}

Except where otherwise noted, content in this journal is licensed under a Creative Commons Attribution 4.0 International Licence. As an open access journal, articles are free to use with proper attribution. ISSN: 2652-4074 (Online) 
argues that while fully or partially automating discretionary EIA decisions is legally and technically problematic, there is significant potential for data-driven decision-making ${ }^{7}$ to provide superior analysis and predictions to better inform EIA processes.

EIAs provide an important mechanism for considering and evaluating the future environmental impacts of a proposed project and can be found in some form across every region of the world, in nations with vastly different political, economic and development contexts. ${ }^{8}$ As EIA processes can be administratively onerous for both proponents and decision-makers, it is unsurprising that proposals for digitising and/or automating EIA processes are emerging in diverse jurisdictions. ${ }^{9}$ For example, as part of the current review of Australia's premier piece of environmental legislation, the Environment Protection and Biodiversity Conservation Act 1999 (Cth) (EPBC Act), one of the issues being explored is whether consideration and approval of low-risk proposals can be automated. ${ }^{10}$ The $E P B C$ Act review thus provides a timely opportunity to assess the advantages and disadvantages of automating EIA processes. Given that the '(likely) significant impact' threshold for EIA processes is a common device in EIA legislation, ${ }^{11}$ the insights yielded from this analysis in the Australian context have transferable relevance to diverse jurisdictions.

In addition to proposals to automate aspects of EIA decisions, there are diverse initiatives aimed at improving digital and datadriven inputs into EIA decision-making processes. For example, the Western Australian Biodiversity Science Institute (WABSI) has proposed a 'digital transformation' of EIA processes, consisting of two primary recommendations. ${ }^{12}$ The first of these is streamlining EIAs by providing digital information flows and tools to aid the assessment process, which involves data aggregation and analysis. ${ }^{13}$ The second recommendation is for a shared analytic framework for the environment, which assists in identifying trends and predicting cumulative impacts. ${ }^{14}$ In a similar vein, recent research in the United Kingdom identifies the need for: data digitisation to systematically collect, transfer, store and access data in a standardised machine-readable format, advanced computer software to assist decision-makers in scoping EIAs, impact modelling to enhance predictive analysis within a digital environment, interactive and accessible environmental statements, and automated post-application monitoring. ${ }^{15}$ We argue that these latter types of digital and automated decision-support tools are preferable to fully or partially automated EIA decisions given their legal and environmental complexity.

This article proceeds in four sections. The second section provides context for the analysis of the opportunities and challenges of automating EIA processes by explaining the nature of both EIAs and ADM. Section 3 contends that discretionary decisionmaking is desirable in EIA processes given their inherently complex and multi-faceted nature. In section 4, we argue that both fully and partially automated decision-making is problematic for EIA decisions as ADM systems have limited capacity to conduct case-by-case analysis that is responsive to changing future scenarios due to their reliance on predetermined or historic inputs. Section 5 proposes that data-driven decision-making can be more appropriately deployed to optimise data, analysis and predictions to inform EIA decision-making processes. We contend that this latter type of ADM can augment EIA decisionmaking processes without displacing the critical role of human discretion in weighing the complex environmental, social and economic considerations at the heart of EIA determinations.

\section{EIAs and ADM}

To analyse what is at stake in automating EIA processes, it is important to first understand both the nature of discretionary EIA decision-making processes, and the nature of ADM. We begin with an overview of EIAs in the Australian setting, which provides important context for evaluating the use of ADM.

The Environment Protection and Biodiversity Conservation Act 1999 (Cth) is the key piece of Commonwealth legislation in Australia's environmental law framework. The Act commenced on 16 July 2000 and established a legal framework to provide for the protection and conservation of nationally and internationally important flora, fauna, ecological communities and heritage

\footnotetext{
${ }^{7}$ Data-driven decision-making refers to the 'practice of basing decisions on the analysis of data rather than purely on intuition': Provost, "Data Science and its Relationship to Big Data and Data-Driven Decision-Making" 53.

${ }^{8}$ See, e.g., Craik, "The Assessment of Environmental Impact," 9-10.

${ }^{9}$ See, e.g., Western Australian Biodiversity Science Institute (WABSI), Digitally Transforming Environmental Assessment; Digital EIA Paper Partners UK, Digitising the Environmental Impact Assessment (EIA) Process.

${ }^{10}$ Graeme, Independent Review of the EPBC Act: Interim Report, 4; Graeme, Independent Review of the EPBC Act: Discussion Paper, 1920.

${ }^{11}$ Arabadjieva, "Vagueness and Discretion in the Scope of the EIA Directive," 418.

12 WABSI, Digitally Transforming Environmental Assessment.

${ }^{13}$ WABSI, Digitally Transforming Environmental Assessment, 22.

${ }^{14}$ WABSI, Digitally Transforming Environmental Assessment, 23.

${ }^{15}$ Digital EIA Project Partners UK, Digitising the Environmental Impact Assessment (EIA) Process, 34.
} 
places, defined as 'matters of national environmental significance'(MNES). ${ }^{16}$ A key mechanism for achieving this aim is an EIA process, consisting of a referral stage and an assessment and approval stage. Under this process, 'controlled actions' are prohibited without an approval issued by the Minister (or authorised by an alternative acceptable process). ${ }^{17}$ If a proponent believes that an action will have, or is likely to have, a significant impact on a MNES, it should be referred to the Minister. ${ }^{18}$ The Minister or the Minister's delegate must then decide whether it is a 'controlled action'. ${ }^{19}$ The screening process is limited to the MNES listed in the Act, including World Heritage sites, ${ }^{20}$ National Heritage places, ${ }^{21}$ wetlands of international importance, ${ }^{22}$ listed threatened species and endangered ecological communities, ${ }^{23}$ listed migratory species, ${ }^{24}$ the Great Barrier Reef Marine Park, ${ }^{25}$ and underground water resources affected by coal mining or coal seam gas developments. ${ }^{26}$ If the action is determined to have such an impact (or likely impact), then it is deemed a 'controlled action', and the authorised decisionmaker must determine what kind of assessment (if any) will be required. Before granting or refusing approval for the controlled action, the decision-maker must consider the environmental impacts of the proposed action, based on proponent documentation, scientific data and departmental advice. ${ }^{27}$

Importantly, the Minister or delegate must consider any matters impacting the relevant controlling provisions and economic and social matters. ${ }^{28}$ This includes taking into account the principles of ecologically sustainable development (ESD), such as the 'conservation of biological diversity', the 'precautionary principle' and 'intergenerational equity', the assessment report (if any) relating to the action, other information generated by the specific assessment approach, and comments received throughout the process. ${ }^{29}$ When making the decision, the Minister or delegate may grant approval with or without conditions. ${ }^{30}$ Proponents must comply with approval conditions, and the Minister may vary, suspend or revoke approvals. ${ }^{31}$

Thus, EIA is a procedural mechanism that is aimed at "predicting the likely effects of a proposed project ... on the environment prior to a decision being made about whether [it] should proceed' ${ }^{32}$ It does not prescribe particular outcomes, even if the EIA process shows that a project will have adverse environmental impacts. The broad discretionary powers granted to the Minister are intended to allow the EIA process to be flexibly applied. This discretion can be valuable as it creates space to consider diverse factors that are likely to have a 'significant impact' across a range of proposals. ${ }^{33}$ However, these broad powers can also have drawbacks, including uncertainty for project proponents regarding their obligations under the Act, and a lack of substantive environmental protections. A recent review of the EPBC Act has criticised the EIA process for being 'convoluted', 'inflexible', 'time consuming' and 'costly'. ${ }^{34}$ As noted above, one of the issues being explored in the EPBC Act review is whether consideration and approval of low-risk EIA proposals can be automated. ${ }^{35}$

To evaluate the desirability of automating EIA processes, it is important to understand the nature of ADM and how it can be used to make or inform decision-making processes. There are two variants of ADM systems that should be distinguished. ${ }^{36}$ The first involves pre-programmed processes which are based on deterministic logic. Informational inputs are entered by a human user with predetermined outcomes. ${ }^{37}$ These generally include rigid 'if-then' statements and are largely incompatible with

\footnotetext{
16 Tomaras, Strengthening the Environment Protection Biodiversity and Conservation Act.

${ }^{17}$ Environment Protection and Biodiversity Conservation Act 1999 s $67 \mathrm{~A}$ ('EPBC Act').

${ }^{18}$ EPBC Act ss 67-74AA.

${ }^{19}$ EPBC Act ss 74B8-79.

${ }^{20} \mathrm{EPBC}$ Act s 13.

${ }^{21}$ EPBC Act s $15 \mathrm{~B}$

22 EPBC Act s 16.

${ }^{23}$ EPBC Act s 18.

${ }^{24}$ EPBC Act s 117.

${ }^{25}$ EPBC Act ss $24 \mathrm{~B}, 24 \mathrm{C}$.

${ }^{26}$ EPBC Act ss 24D, 24E.

${ }^{27}$ EPBC Act ss 95, 98, 103, 108-110, 131-132.

28 EPBC Act s 136.

${ }^{29} \mathrm{EPBC}$ Ac ss $131-132,136(2)$.

${ }^{30}$ EPBC Act ss 133-140.

${ }^{31} E P B C$ Act ss 142-145. Note that the EPBC Act operates concurrently with state and territory legislation, so that activities that require approval through the $E P B C$ Act process may also require approval through mechanisms in other legislation.

32 Holder, Environmental Impact Assessment, 1.

33 Arabadjieva, "Vagueness and Discretion in the Scope of the EIA Directive," 417.

${ }^{34}$ Graeme, Independent Review of the EPBC Act: Interim Report, 41.

${ }^{35}$ Graeme, Independent Review of the EPBC Act: Interim Report, 4; Graeme, Independent Review of the EPBC Act: Discussion Paper, 1920.

${ }^{36}$ Huggins, "Executive Power in the Digital Age: Automation, Statutory Interpretation and Administrative Law," $114-5$.

37 See, e.g., Grimmelmann, "Regulation by Software," 1732.
} 
processing complex data and discretionary decisions. ${ }^{38}$ A key advantage of pre-programmed automated processes is their capacity to produce consistent, efficient and impartial decisions at a far greater scale than human decision-makers. ${ }^{39}$ However, any flaws or errors in pre-programmed systems can be replicated en masse, underscoring the importance of well-designed and appropriately deployed ADM systems.

The second key variant of ADM involves probabilistic processes. These probabilistic processes, often based on machine learning, identify patterns from past data to make inferences and predict future outcomes. ${ }^{40}$ As we demonstrate in section 5 , these types of processes attempt to causally link the likely impacts of a proposed project with potential future environmental impacts. ${ }^{41}$ The superior analytical and predictive power of this type of ADM stems from its capacity to replace hypothesised causal relationships with statistical correlations. ${ }^{42}$ The increasing availability of environmental big data, ${ }^{43}$ combined with sophisticated machine learning analytics, allows for the identification of patterns and trends that were often overlooked, or were indetectable, by humans. ${ }^{44}$ Despite these advantages, it is difficult to understand how probabilistic ADM systems work and why they make the connections they do, which poses challenges to the transparency and explainability of these decisions. ${ }^{45}$

Humans shape the design and implementation of both pre-programmed and probabilistic automated systems in diverse ways. At the design stage, humans make a myriad of choices in negotiating, editing and revising algorithms, and providing the data that automated systems access and interpret. ${ }^{46}$ For EIAs, these discretionary design decisions may include: what data to accumulate, at what point in time to analyse the impacts of a project, whether to consider data surrounding indirect and cumulative impacts, and how to analyse the aggregated data. ${ }^{47}$ At the implementation stage, it can be helpful to conceptualise the extent to which humans are involved in automated processes as a spectrum. At one end of the spectrum are fully automated decisions made without human input after the initial design process. ${ }^{48}$ At the mid-point are partially automated processes that are subject to human oversight and review. At the opposite end of the spectrum, automated decision-support tools may be utilised, yet humans make the final decision. ${ }^{49}$ In sections 4 and 5, we explore the desirability of fully automated, partially automated and automated decision-support tools in the context of EIA decision-making. First, however, we consider the desirability of discretion in EIA decisions.

\section{The Desirability of Discretion in EIA Decisions}

This section argues that, despite the potential drawbacks of discretionary decision-making processes, the exercise of human discretion is critical and desirable for weighing the multiple, competing considerations inherent in EIA decisions. Moreover, discretionary powers allow space for deliberation in a context in which environmental values, facts and scientific understandings are evolving. ${ }^{50}$

Theories of vagueness provide valuable insights into the benefits of framing some EIA decisions, such as the threshold question of whether a project is likely to have a 'significant impact', as a discretionary decision. Vagueness is an inherent feature of most natural languages. ${ }^{51}$ Semantic vagueness is commonly characterised by its failure to draw clear boundaries between opposing interpretations. ${ }^{52}$ As law is a product of language,${ }^{53}$ the presence of vagueness in legislation is 'virtually inevitable'. ${ }^{4}$

\footnotetext{
${ }^{38}$ Sourdin, "Judge v Robot?" 1128.

${ }^{39}$ Crootof, “'Cyborg Justice' and the Risk of Technological-Legal Lock-in,” 237.

${ }^{40}$ Zalnieriute, "The Rule of Law and Automation of Government Decision-Making," 434-435.

${ }^{41}$ See also, Lajaunie, "Big Data Enters Environmental Law," 526.

${ }^{42}$ Lajaunie, "Big Data Enters Environmental Law," 526.

${ }^{43}$ Lajaunie, "Big Data Enters Environmental Law," 526. The distinctive characteristics of big data include its volume, velocity, variety, value and veracity: Younas, "Research Challenges in Big Data" 105-6. For an overview of other definitions and characteristics of big data, see, e.g., Kitchin, "What Makes Big Data, Big Data?" 1-3.

${ }^{44}$ Lajaunie, "Big Data Enters Environmental Law," 527.

45 Zednik, "Solving the Black Box Problem," 3-6; Burrell, "How the Machine "Thinks'," 1-2.

${ }^{46}$ Kitchin, "Thinking Critically about and Researching Algorithms," 18.

${ }^{47}$ The choices made at the design stage have a significant influence over the eventual EIA decision reached: see also Lehr, "Playing with the Data," 657.

${ }^{48}$ Zalnieriute, "The Rule of Law and Automation of Government Decision-Making," 432.

${ }^{49}$ Zalnieriute, "The Rule of Law and Automation of Government Decision-Making," 432.

${ }^{50}$ These arguments build on theories of vagueness articulated by Endicott, Waldron and Arabadjieva: Endicott, "Vagueness in Law"; Waldron, "Vagueness and the Guidance of Action"; Arabadjieva, "Vagueness and Discretion in the Scope of the EIA Directive".

${ }^{51}$ Kompa, "The Role of Vagueness and Context Sensitivity in Legal Interpretation," 205; Spaulding, "Is Human Judgment Necessary?," 376.

${ }^{52}$ Kompa, "The Role of Vagueness and Context Sensitivity in Legal Interpretation," 205.

${ }^{53}$ See, e.g., Vogel, "Computer-Assisted Legal Linguistics," 1340; Condello, "Interpreting and Writing the Law in Digital Society," 1179 , 1185.

${ }^{54}$ Keil, "Vagueness and Law," 8.
} 
Endicott argues that vagueness is not only inevitable but essential to the function of law; vagueness imbues the law with discretion, thereby allowing the space for the consideration of a broad range of relevant factors. ${ }^{55}$ In a similar vein, Waldron argues that discretion is valuable because it requires the decision-maker to engage in a process of active deliberation, or argumentation, ${ }^{56}$ which is particularly important for contested and dynamic fields such as environmental law. ${ }^{57}$

Arabadjieva persuasively argues that Endicott and Waldron's theories of vagueness illuminate the role of discretion in EIA decision-making processes. ${ }^{58}$ First, the open texture of the 'likely significant impact' threshold enables 'any type' of future environmental effects of a proposed project to be considered, as well as 'any extent' to which the environment may be affected. ${ }^{59}$ Secondly, Arabadjieva posits that the open-textured nature of the 'significance' standard in EIA frameworks accommodates the dynamic and evolving nature of environmental issues, and scientific and social understandings of these issues. ${ }^{60}$ Thirdly, the discretionary nature of the significance standard prompts a process of active deliberation, requiring active intellectual engagement and reasoned decision-making on the part of decision-makers. ${ }^{61}$ It is through this active problem-solving process that conflicting values may be identified and negotiated. ${ }^{62}$ In other words, the open-ended, vague nature of the significance standard allows for consideration of a multiplicity of diverse factors and for dynamic subject matter to be actively deliberated and evaluated in light of changing legal, scientific and public perceptions.

In a similar vein to Arabadjieva's arguments about discretionary EIA decision-making in the European Union (EU), we argue that discretion is an inherent and desirable feature of EIA decision-making processes in the context of Australian environmental law. In the decision to approve or enforce conditions on a project, the Minister or delegate considers 'matters relevant' to the protected area, including economic and social matters. ${ }^{63}$ As noted above, this includes taking into account open-textured principles such as ESD, the precautionary principle, and intergenerational equity. ${ }^{64}$ Therefore, discretion under the $E P B C A c t$ is not a failing of the legislation or legal interpretation, nor is it merely an externality of vague language. The $E P B C A c t$ has employed discretionary language to allow scope for the broad consideration of factors that may be relevant to environmental decisions over time and space. ${ }^{65}$ This discretionary process is both deliberate and essential.

Recognising the value of discretion does not ignore that challenges arise where there is vagueness in the law. One significant drawback of the discretionary nature of the EPBC Act's EIA process is the lack of consistency and certainty. ${ }^{66}$ The changing interpretation of what is meant by the 'likely significant impact' threshold can call into question the legitimacy of administrative decision-making. ${ }^{67}$ This uncertainty is aggravated by the lack of a satisfactory accompanying resource where information and data are aggregated in Australia to guide decision-makers through the complex and multi-faceted EIA process. ${ }^{68}$

On balance, we argue that the vagueness of the EIA threshold in the EPBC Act is not a flaw of the framing; rather, it is an essential feature of this contested area of law. While the open-textured terms 'likely significant impact' lack boundaries, they allow for EIAs to operate as 'boundary objects' ${ }^{69}$ — an arrangement for stakeholders with contrasting interests to collaborate and reach a consensus. ${ }^{70}$ The framing of EIAs as discretionary decisions thus has a 'symbolic aspect-it is a signal that the state has decided that this particular activity requires extra scrutiny'. ${ }^{71}$ As such, active intellectual engagement by human decision-makers is needed to adequately take into account diverse and complex factors in EIA decisions.

\footnotetext{
${ }^{55}$ Endicott, "The Value of Vagueness," 28.

${ }^{56}$ Waldron, "Vagueness and the Guidance of Action," 58-65.

${ }^{57}$ See, e.g., Fisher, "Setting the Law Ablaze," 428; Fisher, "Blazing Upstream?," 163.

${ }^{58}$ Arabadjieva, "Vagueness and Discretion in the Scope of the EIA Directive," 419.

${ }^{59}$ Arabadjieva, "Vagueness and Discretion in the Scope of the EIA Directive," 436.

${ }^{60}$ Arabadjieva, "Vagueness and Discretion in the Scope of the EIA Directive," 437.

${ }^{61}$ Arabadjieva, "Vagueness and Discretion in the Scope of the EIA Directive," 440; Waldron, "Vagueness and the Guidance of Action," 62.

${ }^{62}$ Fisher, "Setting the Law Ablaze," 428.

${ }^{63} E P B C$ Act s 136(1)(a)-(b).

${ }^{64}$ The requirement to consider ESD principles is one of the main purposes of the Act: see EPBC Act s 3(1)(b).

${ }^{65}$ Endicott, "The Value of Vagueness," 18; Arabadjieva, "Vagueness and Discretion in the Scope of the EIA Directive," 436.

${ }^{66}$ The challenges of discretion have been raised in many critiques of the EPBC Act to date. See, e.g., Macintosh, "Why the Environment Protection and Biodiversity Conversation Act's Referral, Assessment and Approval Process is Failing to Achieve its Environmental Objectives," 296-301; McGrath, "Key Concepts of the Environment Protection and Biodiversity Conservation Act 1999 (Cth)," 39.

${ }^{67}$ See, e.g., Godden, "The Environment Protection and Biodiversity Conservation Act 1999 (Cth)," 122.

${ }^{68}$ AITHER, Review of Interactions between the EPBC Act and the Agriculture Sector, 38-40.

${ }^{69}$ Fisher, "Jurisdictional' Facts and 'Hot' Facts," 981.

${ }^{70}$ Leigh Star, "This is Not a Boundary Object," 602.

${ }^{71}$ Fisher, "Setting the Law Ablaze," 426.
} 


\section{Fully and Partially Automating EIA Decisions}

In light of the desirability of discretion in EIA decisions, this section argues that, based on current technological capabilities, ADM should not be deployed to fully or partially automate EIA decision-making processes. ADM systems lack the semantic and social dynamism of human decision-makers and face challenges in correctly interpreting and applying discretionary statutory provisions. ${ }^{72}$ Rules-based systems are incompatible with discretionary decision-making, as their potential outputs are dependent on the content of their inputs. ${ }^{73}$ Probabilistic systems present a different array of challenges to discretionary decisionmaking, including barriers to transparency and reliance on historical data. Neither type of ADM is well suited to responding to the semantic and environmental complexities involved in interpreting the 'likely significant impact' threshold. Even if there is a 'human in the loop' who oversees and reviews automated outputs that are relied upon for decision-making purposes, technical complexity and illiteracy, and automation bias all undermine the potential for meaningful human review of partially automated EIA processes. Consequently, the capacity for case-by-case discretionary analysis in EIA decisions is a human attribute that, based on current ADM capabilities, cannot be adequately replicated by automated systems. ${ }^{74}$

Both pre-programmed and probabilistic decision-making tools require the initial step of transforming law into computer code that can be processed by machines. A significant challenge in converting legislative provisions into a machine-executable format is promoting coherence with the rules and principles of statutory interpretation. ${ }^{75}$ Despite sustained efforts to accurately convert legislation into code, challenges persist in achieving alignment with the true meaning of a statute. ${ }^{76}$ Importantly, while statutory interpretation should inform the way both discretionary and non-discretionary statutory provisions are coded, ${ }^{77}$ discretionary terms, such as the 'likely significant impact' threshold, pose particular challenges for ADM. There is a risk that law translated into computer code may narrow the ambit of discretionary powers, favouring strict interpretations of vague principles and increasing the potential for meaning to be misinterpreted. For example, a narrow interpretation of the $E P B C A c t$ could limit its ambit to 'direct' impacts on MNES sites, ${ }^{78}$ rather than the more expansive interpretation of direct and indirect impacts favoured by the courts. ${ }^{79}$

Interestingly, the WABSI's proposal to digitise EIA processes suggests that one of the benefits will be to 'reduce the need to rely on the precautionary principle'. ${ }^{80}$ A claim that technological interventions may decrease reliance on the precautionary principle appears to imply that this aspect of discretionary decision-making is a distracting, expensive and an unnecessary inefficiency. ${ }^{81}$ This relates to a broader concern that the increasing digitisation and automation of government processes will see contextual and discretionary decision-making replaced by more rules-based 'codified justice' ${ }^{82}$ Reducing reliance on discretionary provisions may not be desirable to achieve statutory purposes and nuanced, contextualised outcomes for citizens and the environment.

Importantly, in the absence of statutory reform that removes discretionary powers, it is not legally permissible for the exercise of these powers to be unduly restricted. A constructive failure to exercise a discretionary power is a reviewable error under Australian administrative law, underscoring that ADM systems should not fetter discretionary powers. ${ }^{83}$ More broadly, there is an administrative law assumption that discretionary powers will be exercised by an agent capable of understanding both the complexity of legal instruments and the dynamic environment in which a particular exercise of statutory powers occurs. ${ }^{84}$ There is a concomitant expectation that administrative decision-makers are able to provide adequate reasons about why an outcome was reached in a particular case, which in most instances is beyond the current capacities of ADM systems. ${ }^{85}$

\footnotetext{
${ }^{72}$ Huggins, "Executive Power in the Digital Age," 121; Bateman, "Algorithmic Decision-Making and Legality," 520.

${ }^{73}$ Hildebrandt, "Algorithmic Regulation and the Rule of Law," 2.

${ }^{74}$ See also, Binns, "Human Judgment in Algorithmic Loops," 11, 19.

${ }^{75}$ Huggins, "Executive Power in the Digital Age," 112-113.

${ }^{76}$ Ashley, "Artificial Intelligence and Legal Analytics," 38-72.

${ }^{77}$ Huggins "Executive Power in the Digital Age," 120-121.

${ }^{78}$ Under such an interpretation, 'direct' impacts would include only the immediate and physical impacts to the protected area that could be causally linked to anthropogenic action taken within its boundaries: Godden, "The Environment Protection and Biodiversity Conservation Act 1999 (Cth)," 119.

${ }^{79}$ See, e.g., Minister for the Environment and Heritage v Queensland Conservation Council Inc (2004) 139 FCR 24 (2004) 139 FCR $24,38-$ 9 (Black CJ, Ryan and Finn JJ).

${ }^{80}$ WABSI, Digitally Transforming Environmental Assessment, 9, 12, 19, 21.

${ }^{81}$ For similar arguments, see Crootof, “'Cyborg Justice' and the Risk of Technological-Legal Lock-in,” 233.

${ }^{82}$ Crootof, “'Cyborg Justice' and the Risk of Technological-Legal Lock-in,” 245.

${ }^{83}$ Perry, "iDecide: Digital Pathways to Decision."

${ }^{84}$ Bateman, "Algorithmic Decision-Making and Legality: Public Law Dimensions," 523-6.

85 Bateman, "Algorithmic Decision-Making and Legality: Public Law Dimensions," 526-7.
} 
Prima facie, well-designed probabilistic systems potentially have greater scope to accommodate the complex factors considered in EIA decisions than pre-programmed ADM systems. An advantage of these more sophisticated probabilistic models is that they may over time be able to distinguish the relevant combinations of facts to allow decisions that are more context specific. ${ }^{86}$ Using ADM to make EIA decisions would require historical data of previous EIA decisions to be included as an input in order for the probabilistic system to learn what impacts are taken into account, what weight they are given, and the outcome based on the facts. However, the varying interpretations of vague EIA provisions have not been linear. In addition, while machine learning can consider differences in data inputs, it cannot alter a decision based on a variable that was not used in the training set. ${ }^{87}$ Relying on previous interpretations of the 'likely significant impact' threshold would result in a reproduction of what is already known. ${ }^{88}$ With the last State of the Environment report demonstrating a downward trend in native plant species, wetlands, coral reefs (including the Great Barrier Reef), small mammals, reptiles, amphibians and shorebirds across Australia, ${ }^{89}$ a reproduction of historical interpretations of the 'likely significant impact' threshold is arguably not what is needed. Indeed, without adequate foresight, automating EIA decisions could reinforce historical decisions that have degraded the natural environment. This 'business as usual' approach is particularly dangerous because environmental consequences become less tractable over time, and the capacity to reverse the damage becomes less viable. ${ }^{90}$

Moreover, not all impacts and uncertainties are practically measurable through modelling techniques. For example, although technologies to support EIA decisions may be capable of predicting the likely carbon emissions from proposed projects, this is not a sufficient proxy for its likely impacts. ${ }^{91}$ Even a combination of data sources, such as tree cover impacts, carbon sequestration loss and soil depletion, is not an accurate equivalent for the 'likely significant impact' assessment. While data may inform an assessment of the likely biophysical impacts, it does not account for evolving social understandings of what impacts are 'significant' in the context of environmental law, ${ }^{92}$ nor does it reflect the social, cultural and intergenerational implications of environmental degradation. ${ }^{93}$ The failure to account for uncertainty in probabilistic systems leads to poor decisions with a higher risk of negative outcomes derived from the system's error margins. ${ }^{94}$ As the impacts of current projects on future environmental conditions are inherently uncertain, human intellectual processes are still required. Human decisionmakers are sensitive to context in a way that technological systems currently cannot be, particularly when considering the variable temporal scales, and geographic and cultural environments, in which EIA decisions are made.

On balance, ADM systems are not yet capable of accommodating the semantic and environmental complexities involved in discretionary EIA decision-making. While probabilistic systems are preferable to pre-programmed systems, even sophisticated variants of the former are limited by their training data and may not be adequately responsive to novel and dynamic contexts. Fully automated decision-making is thus likely to be legally and technically problematic in the EIA context. Hence, it is relevant to consider whether it is instead preferable if there is a 'human in the loop' who oversees and reviews automated outputs that are relied upon for decision-making purposes.

Before proceeding, it is useful to clarify what is meant by meaningful human input. Although Australia does not currently have legislative protections for ADM equivalent to those in the EU's General Data Protection Regulation (GDPR), ${ }^{95}$ the understanding of meaningful human involvement adopted under the GDPR is valuable for present purposes. The relevant interpreting authority ${ }^{96}$ for the GDPR specifies that meaningful involvement includes the review of automated outputs by someone with the authority and competence to change the decision and who has considered all the relevant data. ${ }^{97}$ If a human is merely 'rubber stamping' a decision suggested by automated outputs, this will not constitute meaningful human involvement and will not be sufficient to avoid the prohibition on solely automated decisions under Article 22 of the GDPR.

\footnotetext{
${ }^{86}$ Administrative Review Council, Automated Assistance in Administrative Decision Making, Report No 46 (2004) 9.

${ }^{87}$ Cobbe, "Administrative Law and the Machines of Government," 641.

${ }^{88}$ Condello, "Interpreting and Writing the Law in Digital Society," 1178.

${ }^{89}$ Department of Environment and Energy, Australia State of the Environment Report, 27-8.

90 See, e.g., Young, "Why is it Hard to Solve Environmental Problems?," 5-19.

${ }^{91}$ Gradient Institute, Practical Challenges For Ethical AI, 7.

${ }^{92}$ Arabadjieva, "Vagueness and Discretion in the Scope of the EIA Directive," 419.

${ }^{93}$ See, e.g., Kirby, "Environmental and Planning Law in the Age of Human Rights and Climate Change," 181.

${ }^{94}$ Gradient Institute, Practical Challenges For Ethical AI, 13.

${ }^{95}$ Regulation (EU) 2016/679 of the European Parliament and of the Council of 27 April 2016 on the Protection of Natural Persons with Regard to the Processing of Personal Data and on the Free Movement of such Data, and Repealing Directive 95/46/EC (General Data Protection Regulation), OJ 2016 L 119/1 ('GDPR') art 22.

${ }^{96}$ GDPR art 68. Note the European Data Protection Board was formerly the Article 29 Working Party.

${ }^{97}$ Article 29 Data Protection Working Party (A29WP), "Guidelines on Automated Individual Decision-making and Profiling for the Purposes of Regulation 2016/679 (wp251rev.01)" 21 <https://ec.europa.eu/newsroom/article29/item-detail.cfm?item_id=612053>.
} 
Significantly, however, it is difficult to draw crisp distinctions between human and automated influences on a decision due to the challenges posed by opacity, automation bias and the lack of technical literacy on the part of some decision-makers. As Burrell notes, opacity can arise from the deliberate concealment of an algorithm for reasons such as protecting trade secrets or maintaining competitive advantage. ${ }^{98}$ In addition, technical literacy challenges experienced by the vast majority of the population who cannot read and write code can render algorithms opaque and incomprehensible, even if their source code is made transparent. ${ }^{99}$ Moreover, a machine learning algorithm that has self-learning properties may produce outcomes that cannot be intuitively explained, even by programming experts. ${ }^{100}$ Although there is a growing body of research attempting to develop techniques to explain these outputs, ${ }^{101}$ explanations of how algorithmic decisions are made may not meet legal expectations of reason-giving that explain why a particular decision was made. ${ }^{102}$

Automation bias complicates the task of overseeing and reviewing automated outputs. This type of bias refers to humans' susceptibility to defer to a computer program's outputs due to a perception that such outputs are superior or even infallible. ${ }^{103}$ As a result, decision-makers tend to trust and accept the outputs of automated processes without further scrutiny. ${ }^{104}$ This deference to computerised outputs fails to adequately account for the risks discussed above that automated processes can produce erroneous outputs due to flaws in the system's design, data inputs or underlying code. Thus, even when a process is only partially automated, there is a risk that there will be a lack of critical evaluation of the computer-generated outputs.

A related factor that contributes to undue reliance on computerised processes is that the decision-maker may lack the technical literacy required for the critical assessment of automated outputs. As Hildebrandt notes, in many situations, the decision-maker may not understand how the automated system was programmed or works and the 'reasons' underpinning its outputs. ${ }^{105}$ As Bennett Moses has argued in the context of lawyers, decision-makers need to understand that 'while computer programs are not "disobedient", they can rely on erroneous assumptions, contain flawed logic or be programmed to draw inferences that may be right most of the time, but wrong in a specific instance'. ${ }^{106}$ Similarly to automation bias, decision-makers' lack of understanding of the reasons underpinning automated processes can induce compliance with their outputs due to the perception that they outperform human expertise. ${ }^{107}$

It is also critical that meaningful human oversight is available at the review stage. Currently, the EPBC Act establishes three pathways in which a person can seek a review or reconsideration of an administrative decision: request for reconsideration, merits review and judicial review. Reconsideration of decisions can occur if a proposed action is deemed 'clearly unacceptable' or a 'controlled action'; 108 however, this power is only available in limited circumstances. ${ }^{109}$ Merits review, undertaken by the Administrative Appeals Tribunal, is only allowed for specified types of decisions made by a delegate. ${ }^{110}$ Notably, merits review is unavailable for most of the key decisions about EIAs and project approvals, regardless of the status of the decision-maker. ${ }^{111}$ Thus, challenges to ministerial decisions under the EPBC Act are often limited to judicial review. ${ }^{12}$ Under Australia's strict separation of powers, courts can supervise the process by which decisions under the EPBC Act are made but cannot reconsider the appropriateness of the substantive decision or its consequences.

In reconciling the tension between the 'likely significant impact' threshold's open-textured nature and the judiciary's role in placing appropriate limits on the discretionary powers of administrative decision-makers, Australian courts have adopted a variety of approaches to reviewing EIA decisions. Fisher divides these approaches into two groups. First, EIA decisions have been successfully reviewed under conventional grounds of judicial review of discretion, including the irrelevant/relevant

\footnotetext{
${ }^{98}$ Burrell, "How the Machine 'Thinks'," 3-4.

99 Burrell, "How the Machine "Thinks'," 4-5.

${ }^{100}$ Coglianese, "Regulating by Robot," 1167; Grimmelmann, "Regulation by Software," 1734-1735; Burrell, "How the Machine 'Thinks'," 4-12.

${ }^{101}$ See, e.g., Lipton, “The Mythos of Model Interpretability,”; Zerilli, “Transparency in Algorithmic and Human Decision-Making,” 661683.

102 Cobbe, "Administrative Law and the Machines of Government," 648.

${ }^{103}$ Skitka, "Accountability and Automation Bias," 714-716; Carr, The Glass Cageman.

${ }^{104}$ McMillan, Automated Assistance to Administrative Decision-Making, 2.

${ }^{105}$ Hildebrandt, "Algorithmic Regulation and the Rule of Law," 2.

106 Bennett Moses, "The Need for Lawyers," 359-360.

${ }^{107}$ Hildebrandt, "Algorithmic Regulation and the Rule of Law," 2.

${ }^{108}$ EPBC Act ss 75, 78.

${ }^{109}$ Department of the Environment, Water, Heritage and the Arts, The Australian Environment Act, 311.

${ }^{110}$ See EPBC Act 303GJ.

${ }^{111}$ Law Council of Australia, Statutory Review of the Environment Protection and Biodiversity Conservation Act 1999 (Cth), 37-41; Department of the Environment, Water, Heritage and the Arts, The Australian Environment Act, 317.

${ }^{112}$ At the Commonwealth level, judicial review can be initiated under the Administrative Decisions (Judicial Review) Act 1977 (Cth) or the Judiciary Act 1903 (Cth) s 39B.
} 
considerations grounds and unreasonableness. ${ }^{113}$ The second approach taken by the courts is to interpret the 'likely significant impact' threshold as a jurisdictional fact - a criterion that must be satisfied before the power of a decision-maker can be enlivened. ${ }^{114}$ Additional grounds of review that may apply in the context of automated EIA decision-making include inflexible application of a rule or policy, a constructive failure to exercise discretion, and issues of prejudgment or bias. ${ }^{15}$ Again, however, important questions arise as to whether courts will be able to engage in meaningful review of automated processes. Examining, understanding and scrutinising the code and data underlying automated systems may be beyond the technical expertise of many members of the judiciary. 116

Therefore, while automating EIA processes may improve efficiency, it is also likely to limit the responsiveness of EIAs to semantic complexity and dynamic environmental conditions. If ADM is used to partially automate the discretionary EIA decision-making process, opportunities for meaningful human oversight and review are likely to be undermined by the opacity and complexity of automated systems, automation bias and technical literacy challenges. Accordingly, until ADM systems are capable of interpreting the complexity of legal instruments, making contextualised decisions, and providing transparent reasons for their outputs, the legal standards necessary for the exercise of EIA decision-making powers will not be met. However, this is not to say that ADM cannot valuably support decision-making in complex scenarios. Indeed, there is significant scope for ADM to improve data analysis on the state of the environment and the trajectory of environmental change to better inform EIA decision-making, to which we now turn.

\section{Data-Driven Decision-Making}

ADM has significant potential to enhance the detection of patterns in data, which can enable a deeper understanding of the interlinkages and complexities of ecosystems, and likely future impacts. This section therefore argues that instead of automating the decision-making process itself, ADM can be valuably harnessed to improve data analysis and predictions to inform EIA decisions. This type of data-driven decision-making in EIAs has the potential to optimise the unique capabilities of automated systems without displacing the critical role of human discretion.

First, digital and automated tools can aggregate and analyse extremely large quantities of data, which can reduce knowledge gaps and facilitate the quantification and codification of environmental observations to inform EIA decisions. Big data, which is characterised by its volume, velocity, variety, value and veracity, ${ }^{117}$ is now permeating environmental decision-making. ${ }^{118}$ Increasingly, ecosystems, biodiversity and natural resources have a digital correlate. For example, aerial imaging techniques are able to create high-resolution images of agricultural land, geological structures and fishing grounds, and molecular readout technologies are capable of categorising genomes of diverse species populations. ${ }^{119}$ As a consequence, there are large bodies of 'geospatial, genetic, biochemical and phenotypic data' being aggregated. ${ }^{120}$ These large data sets can be analysed and converted into knowledge to inform EIA decisions.

The value of big data is enhanced by data analysis, or big data analytics, to identify trends and correlations in large datasets. The sheer volume of environmental data that is now available can render traditional statistical models ineffective in deriving meaningful insights to inform decision-making. ${ }^{121}$ Instead, machine learning and neural networks ${ }^{122}$ are increasingly being used to identify trends in historical environmental data and provide decision-support tools in diverse contexts, including biodiversity and environmental protection, and mitigating and adapting to the impacts of climate change. ${ }^{123}$

\footnotetext{
${ }^{113}$ See, e.g., Fisher, “'Jurisdictional' Facts and 'Hot' Facts,” 985; Minister for the Environment and Heritage v Queensland Conservation Council Inc (2004) 139 FCR 24.

${ }^{114}$ Fisher, “Jurisdictional' Facts and 'Hot' Facts," 977; Corporation of the City of Enfield v Development Assessment Commission (2000) 199 CLR 135, 158 [59].

${ }^{115}$ See also Miller, "The Application of Administrative Law Principles to Technology-Assisted Decision-Making," 23-24; Perry, "iDecide: Administrative Decision-Making in the Digital World," 33.

${ }^{116}$ Miller, "The Application of Administrative Law Principles to Technology-Assisted Decision-Making," 26-28; Perry, "iDecide: Digital Pathways to Decision".

${ }^{117}$ See, e.g., Younas, "Research Challenges in Big Data," 105. For an overview of other definitions and characteristics of big data, see, e.g., Kitchin, "What Makes Big Data, Big Data?," 1.

118 Lajaunie, "Big Data Enters Environmental Law," 523.

${ }^{119}$ Bruynseels, "When Nature Goes Digital," 343.

${ }^{120}$ Bruynseels, "When Nature Goes Digital," 347-348.

${ }^{121}$ Lajaunie, "Big Data Enters Environmental Law," 526.

${ }^{122}$ LeCun, "Deep Learning," 436.

${ }^{123}$ Lajaunie, "Big Data Enters Environmental Law," 527.
} 
An important contribution of machine learning tools in this context is the capacity to identify patterns from examples, historical data and experience to make future predictions, which are often - but not always - highly accurate. ${ }^{124}$ This is particularly important for EIA decisions, which involve judgments on the likelihood of impacts, or the future possibility of the occurrence of an event. Data interpretation and mining techniques, which involve analysing data to detect patterns and identify potential problems or opportunities, or to discover similarities between current and past situations, may help to improve decision-makers' understanding of both the direct and cumulative impacts of a project, including insights from the data that may have been missed through human analysis. ${ }^{125}$ For example, machine learning techniques have been shown to improve weather and microclimate modelling ${ }^{126}$ and predicting areas with climate-related flood risks. ${ }^{127}$ With the cumulative impacts of proposals increasingly being recognised as a relevant factor in EIAs, ${ }^{128}$ data-driven decision-making has the potential to optimise decision-makers' capacity to understand the interaction between complex data sets and predict the cumulative impacts of projects.

In addition, Glicksman et al. suggest that the technological transformation of environmental governance can affect not only the outcomes of environmental decision-making but also who is involved in governing the environment. ${ }^{129}$ New environmental technologies open up possibilities for a diverse range of actors to adopt more active roles in the EIA process. Individuals, groups and communities increasingly have access to devices, which are capable of measuring, monitoring and reporting environmental data. ${ }^{130}$ For example, citizens can use aerial imaging technologies or mobile devices to record environmental conditions and report to environmental decision-makers remotely. ${ }^{131}$ This 'democratisation' of data may also promote public participation, transparency and accountability in environmental decision-making processes. ${ }^{132}$ Despite these possibilities, the responsibility for environmental data collection and analysis should not be shifted to unpaid individual citizens. The need for large quantities of standardised data across diverse landscapes will require both government funding and cooperation between relevant government agencies. ${ }^{133}$

Beyond the initial EIA decision, technological advances also have the potential to promote compliance with environmental law. ${ }^{134}$ The promotion and use of digital technologies can help regulated entities, the government and the public more easily monitor pollutant discharges, environmental changes and non-compliance with the conditions associated with EIA approvals. ${ }^{135}$

Of course, the use of digital and automated tools to inform EIA decisions is not without technical and legal challenges. From a technical perspective, key issues include gaps in data availability and access, the comparability of data collected at varying levels of temporal and spatial detail, and the heterogeneity of methods and computer systems used in the collection process, which means that some data formats are not compatible with all software systems. ${ }^{136}$ In addition to concerns about the quality of data inputs, erroneous algorithmic outputs can stem from the way algorithms are designed and used. For example, errors can arise from mistranslating the problem for the algorithm to solve, miscoding the law or rules upon which the decision should be based, bugs in the code, ${ }^{137}$ or humans' tendency to defer to digital outputs. ${ }^{138}$ In light of the limitations of ADM outlined in the previous sections, including their tendency to replicate historical patterns and biases, human decision-makers should at a

${ }^{124}$ Zalnieriute, "The Rule of Law and Automation of Government Decision-Making," 427; Lajaunie, "Big Data Enters Environmental Law," 527.

${ }^{125}$ Cortés, "Artificial Intelligence and Environmental Decision Support Systems," 78.

126 See, e.g., Chlingaryan, "Machine Learning Approaches for Crop Yield Prediction and Nitrogen Status Estimation in Precision Agriculture," 62.

${ }^{127}$ Mosavi, "Flood Prediction Using Machine Learning Models," 1536.

${ }^{128}$ See, e.g., Godden, "The Environment Protection and Biodiversity Conservation Act 1999 (Cth)," 119; Dales, "Death by a Thousand Cuts," 149 .

${ }^{129}$ Glicksman, "Technological Innovation, Data Analytics and Environmental Enforcement," 87.

${ }^{130}$ See, e.g., Breggin, "Big Data and the Environment," 10985; citing Snyder, “The Changing Paradigm of Air Pollution Monitoring," 11373 , 11375

${ }^{131}$ Bruynseels, "When Nature Goes Digital," 343.

${ }^{132}$ Glicksman, "Technological Innovation, Data Analytics and Environmental Enforcement," 36; Fahey, "The Democratization of Big Data," 325.

${ }^{133}$ Van Dijk, "Environmental Reporting and Accounting in Australia: Progress, Prospects and Research Priorities," $343-4$.

${ }^{134}$ Glicksman, "Technological Innovation, Data Analytics and Environmental Enforcement," 49. See also, Macey, "The Architecture of Ignorance," 1641.

${ }^{135}$ See, e.g., Solomon, "Detecting and Understanding Non-Compliance with Conservation Rules," 2.

${ }^{136}$ See, e.g., Australian Government, Data Availability and Use, 165-166; Hand, Dark Data: Why What You Don’t Know Matters; Squires,

"Rethinking the Commons Problem," 2-3. As governments increasingly digitise environmental data and develop consistent methods of collection, there is an opportunity to promote data pooling, both within sovereign borders and transnationally: see, e.g., Potts, "Governing the Innovation Commons," 1031.

${ }^{137}$ Kitchin, "Thinking Critically about and Researching Algorithms," 17.

${ }^{138}$ See, e.g., Skitka, "Accountability and Automation Bias," 701; Carr, The Glass Cage. 
minimum understand the appropriate uses and limitations of automated systems before considering their outputs in EIA decision-making processes. Further, there are potential legal challenges associated with surveillance and privacy, ${ }^{139}$ the fairness and transparency of black box automated processes, ownership of and access to data, and the evidentiary and probative value of digital information. ${ }^{140}$ While these technical and legal challenges need to be acknowledged and addressed, on balance, datadriven decision-making has a valuable role to play in enhancing the accuracy and completeness of environmental analysis and predictions informing human-led EIA decisions.

\section{Conclusion}

As governments throughout the world face pressure to address accelerating environmental degradation, ADM has been proposed as a means of improving EIA decisions. This article has highlighted the opportunities and challenges of integrating ADM into this decision-making process, using EIAs in Australia as an illustrative example. It has argued that human discretion has a valuable role to play in EIA processes to ensure that decision-makers actively grapple with complex and multi-faceted environmental challenges. Current technologies do not have the capacity to employ the same level of discretionary judgment and contextualisation as human decision-makers. Even for partially automated decisions, there are significant obstacles to meaningful human involvement arising from technical complexity and illiteracy, and automation bias. Using ADM to partially or fully automate discretionary EIA decisions is at odds with the semantic and environmental complexities of these decisions. Thus, the interpretation of the 'likely significant impact' threshold should remain subject to a distinctly human process of discretionary decision-making. Given that this type of decision-making threshold is commonly used in EIA legislation, ${ }^{141}$ this recommendation has transferable relevance to diverse jurisdictions.

However, the choice to integrate ADM into EIAs is not limited to automating discretionary decisions. Data-driven decisionmaking tools can also be harnessed to enhance environmental analyses and predictions to better inform EIA decisions. As environmental challenges compound, EIA processes are required to consider the complex, indirect and cumulative impacts of proposed projects. ADM can enhance EIA decisions by improving the capacity to aggregate and analyse environmental data, identify trends and patterns in data to enable a deeper understanding of ecosystem complexities and interlinkages, and forecast cumulative impacts. More broadly, digital and automated tools can enhance the capacity for diverse stakeholders to identify, measure, analyse, predict, engage with and monitor the environmental impacts of proposed projects. ${ }^{142}$ In these ways, there is significant potential for ADM to improve the accuracy and completeness of EIA decisions without displacing the critical role of humans in discretionary decision-making processes.

\footnotetext{
${ }^{139}$ See, e.g., Regulation (EU) 2016/679 of the European Parliament and of the Council of 27 April 2016 on the Protection of Natural Persons with Regard to the Processing of Personal Data and on the Free Movement of such Data, and Repealing Directive 95/46/EC (General Data Protection Regulation), OJ 2016 L 119/1.

${ }^{140}$ See, e.g., Coglianese, "Deploying Machine Learning for a Sustainable Future," 6; Purdy, 'Satellites," 410-412; Markowitz, "Legal Challenges and Market Rewards to the Use and Acceptance of Remote Sensing and Digital Information as Evidence," $220-243$.

${ }^{141}$ Arabadjieva, "Vagueness and Discretion in the Scope of the EIA Directive," 418.

${ }^{142}$ See, e.g., Glicksman, "Technological Innovation, Data Analytics and Environmental Enforcement," 46.
} 


\section{Bibliography}

\section{Secondary Sources}

Administrative Review Council. Automated Assistance in Administrative Decision Making. (Report No 46 2004).

AITHER. Review of Interactions between the EPBC Act and the Agriculture Sector: Final Report. (28 September 2018).

Arabadjieva, Kalina. "Vagueness and Discretion in the Scope of the EIA Directive." Journal of Environmental Law 29, no 3 (2017): 417-444. https://doi.org/10.1093/jel/eqx011.

Ashley, Kevin. Artificial Intelligence and Legal Analytics: New Tools for Law Practice in the Digital Age. Cambridge: Cambridge University Press, 2017.

Bateman, Will. "Algorithmic Decision-Making and Legality: Public Law Dimensions.” Australian Law Journal 93 (2020): 520-530.

Bennett Moses, Lyria. "The Need for Lawyers." In The Future of Australian Legal Education: A Collection, edited by Kevin Lindgren, Francois Kunc and Michael Coper, 355-372. Pyrmont: Thomson Reuters, $1^{\text {st }}$ ed, 2018.

Bice, Sara, and Thomas Fischer. "Impact Assessment for the $21^{\text {st }}$ Century: What Future?" Impact Assessment and Project Appraisal 38, no 2 (2020): 89-93. https://doi.org/10.1080/14615517.2020.1731202

Binns, Reuben. "Human Judgment in Algorithmic Loops: Individual Justice and Automated Decision-Making." Regulation \& Governance (2020): 1-15. https://doi.org/10.1111/rego.12358

Breggin, Linda and Judith Amsalem. "Big Data and the Environment: A Survey of Initiatives and Observations Moving Forward." Environmental Law Reporter: News \& Analysis 44, no 11 (2014): 10984.

Bruynseels, Koen. "When Nature Goes Digital: Routes for Responsible Innovation." Journal of Responsible Innovation 7, no 3 (2020): 342-360. https://doi.org/10.1080/23299460.2020.1771144

Burrell, Jenna. "How the Machine 'Thinks': Understanding Opacity in Machine Learning Algorithms." Big Data \& Society 3, no 1 (2016): 1-12. https://doi.org/10.1177\%2F2053951715622512

Carr, Nicholas. The Glass Cage: Where Automation is Taking Us. Random House, 2015.

Chlingaryan, Anna, Salah Sukkarieh, and Brett Whelan. "Machine Learning Approaches for Crop Yield Prediction and Nitrogen Status Estimation in Precision Agriculture: A Review." Computers and Electronics in Agriculture 151 (2018): 61-69. https://doi.org/10.1016/j.compag.2018.05.012.

Citron, Danielle. “Technological Due Process.” Washington University Law Review 85, no 6 (2008): 1249-1313. https://openscholarship.wustl.edu/law_lawreview/vol85/iss6/2.

Citron, Danielle, and Ryan Calo. "The Automated Administrative State: A Crisis of Legitimacy." Emory Law Journal (forthcoming, 2021): 1-50. https://scholarship.law.bu.edu/faculty_scholarship/838.

Cobbe, Jennifer, "Administrative Law and the Machines of Government: Judicial Review of Automated Public-Sector Decision-Making" Legal Studies 39, no 4 (2019): 636-655. https://doi.org/10.1017//st.2019.9.

Coglianese, Cary, and David Lehr. "Regulating by Robot: Administrative Decision Making in the Machine-Learning Era." Georgetown Law Journal 105, no 5 (2017): 1147-1223. https://scholarship.law.upenn.edu/faculty_scholarship/1734.

Coglianese, Cary. "Deploying Machine Learning for a Sustainable Future.” Public Law and Legal Theory Research Paper Series, Research Paper No. 20-17 (2020): 1-10. https://doi.org/10.2307/j.ctvqc6gcq.26.

Condello, Angela. "Interpreting and Writing the Law in Digital Society: Remarks on a Shift of Paradigm." International Journal for the Semiotics of Law (2020): 1175-1186. https://doi.org/10.1007/s11196-020-09733-6.

Cortés, U., M. Sànchez-Marrè, L. Ceccaroni, I. R-Roda and M. Poch. "Artificial Intelligence and Environmental Decision Support Systems." Applied Intelligence 13 (2000): 77-91. https://doi.org/10.1023/A:1008331413864.

Craik, Neil. "The Assessment of Environmental Impact." In The Oxford Handbook of Comparative Environmental Law, edited by Emma Lees and Jorge E. Viñuales, 876-902. Oxford: Oxford University Press, 2019.

Crootof, Rebecca. "'Cyborg Justice' and the Risk of Technological-Legal Lock-in.” Columbia Law Review Forum 119 (2019): 233-251. https://columbialawreview.org/content/cyborg-justice-and-the-risk-of-technological-legal-lock-in/.

Dales, Jessica. "Death by a Thousand Cuts: Incorporating Cumulative Effects in Australia's Environment Protection and Biodiversity Conservation Act.” Pacific Rim Law and Policy Journal 20, no 1 (2011): 149-178. https://digitalcommons.law.uw.edu/wilj/vol20/iss1/6.

Data Protection Working Party. Guidelines on Automated Individual Decision-making and Profiling for the Purposes of Regulation 2016/679. (3 October 2017).

Department of the Environment, Water, Heritage and the Arts. The Australian Environment Act: Report of the Independent review of the Environment Protection and Biodiversity Conservation Act 1999 (Australian Government, 2009).

Department of Environment and Energy. Australia State of the Environment Report. (Australian Government, 2016).

Digital EIA Paper Partners UK. Digitising the Environmental Impact Assessment (EIA) Process: A User-centred Approach to Designing an EIA Process for the Future. (March 2020). 
Dusík, Jiří, Riki Therivel, Barry Sadler, Thomas Fischer and Ivana Šarić. Strategic Environmental and Social Assessment of Automation (Scoping Working Paper, July 2018).

Endicott, Timothy. "The Value of Vagueness." In Philosophical Foundations of Language in the Law, edited by Andrei Marmor and Scott Soames, 14-30. Oxford: Oxford University Press, 2011.

Endicott, Timothy. Vagueness in Law. Oxford: Oxford University Press, 2000.

Fahey, Sean. "The Democratization of Big Data.” Journal of National Security Law and Policy 7 (2014): $325-331$. https://jnslp.com/2014/05/08/the-democratization-of-big-data/.

Fisher, Elizabeth. "Blazing Upstream? Strategic Environmental Assessment as "Hot" Law." In The Strategic Environmental Assessment Directive: A Plan for Success, edited by Gregory Jones and Eloise Scotford, 161-184. Oxford: Hart Publishing, 2017.

Fisher, Elizabeth. "Environmental Impact Assessment: 'Setting the Law Ablaze'." In Research Handbook on Fundamental Concepts of Environmental Law, edited by Douglas Fisher, 422-448. Cheltenham: Edward Elgar Publishing, 2016.

Fisher, Elizabeth. "'Jurisdictional' Facts and 'Hot' Facts: Legal Formalism, Legal Pluralism, and the Nature of Australian Administrative Law." Melbourne University Law Review 28, no 3 (2015): 968-995.

Glicksman, Robert, David Markell and Claire Monteleoni. "Technological Innovation, Data Analytics and Environmental Enforcement.” Ecology Law Quarterly 44, no 1 (2017): 41-88. https://dx.doi.org/10.15779/Z38GX44T46.

Godden, Lee and Jacqueline Peel. "The Environment Protection and Biodiversity Conservation Act 1999 (Cth): Dark Sides of Virtue." Melbourne University Law Review 31, no 1 (2007): 106-145.

Graeme, Samuel. Independent Review of the EPBC Act: Discussion Paper. (Commonwealth of Australia, November 2019).

Graeme, Samuel. Independent Review of the EPBC Act: Interim Report. (Commonwealth of Australia, June 2019).

Gradient Institute. Practical Challenges for Ethical AI. (White Paper, 3 December 2019).

Grimmelmann, James. "Regulation by Software.” Yale Law Journal 114 (2005): 1719-1758. https://digitalcommons.law.yale.edu/ylsspps_papers/46.

Hand, David. Dark Data: Why What You Don't Know Matters. Princeton: Princeton University Press, 2020.

Hildebrandt, Mireille. "Algorithmic Regulation and the Rule of Law." Philosophical Transactions of the Royal Society A: Maths, Physics and Engineering Sciences 376, no 2128 (2018) 1-11. https://doi.org/10.1098/rsta.2017.0355.

Holder, Jane. Environmental Impact Assessment: The Regulation of Decision Making. Oxford: Oxford University Press, 2004.

Huggins, Anna. "Executive Power in the Digital Age: Automation, Statutory Interpretation and Administrative Law." In Interpreting Executive Power, edited by Janina Boughey and Lisa Burton Crawford, 111-128. Alexandria: Federation Press, 2020.

Keil, Geert and Ralf Poscher. "Vagueness and Law." In Vagueness and Law: Philosophical and Legal Perspectives, edited by Geert Keil and Ralf Poscher, 1-20. Oxford: Oxford University Press, 2016.

Kirby, Michael. "Environmental and Planning Law in the Age of Human Rights and Climate Change." Environment and Planning Law Journal 36, no 3 (2019): 181-196.

Kitchin, Rob. "Thinking Critically About and Researching Algorithms." Information, Communication and Society 20 , no 1 (2017): 14-29. https://doi.org/10.1080/1369118X.2016.1154087

Kitchin, Rob, and Gavin McArdle. "What Makes Big Data, Big Data? Exploring the Ontological Characteristics of 26 Datasets." Big Data \& Society Jan-June (2016): 1-10. https://doi.org/10.1177\%2F2053951716631130

Kompa, Nikola. "The Role of Vagueness and Context Sensitivity in Legal Interpretation.” In Vagueness and Law: Philosophical and Legal Perspectives, edited by Geert Keil and Ralf Poscher, 205-227. Oxford: Oxford University Press, 2016.

Law Council of Australia. Statutory Review of the Environment Protection and Biodiversity Conservation Act 1999 (Cth). (20 April 2020).

LeCun, Y, Y Bengio and G Hinton. “Deep Learning.” Nature 521, no 7553 (2015): 436-444. https://doi.org/10.1038/nature14539.

Leigh Star, Susan. "This is Not a Boundary Object: Reflections on the Origin of a Concept." Science, Technology and Human Values 35 (2010): 601-617. https://doi.org/10.1177\%2F0162243910377624

Lajaunie, Claire, Burkhard Schafer and Pierre Mazzega. "Big Data Enters Environmental Law.” Transnational Environmental Law 8, no 3 (2019): 523-545. https://doi.org/10.1017/S2047102519000335.

Lehr, David, and Paul Ohm. "Playing with the Data: What Legal Scholars Should Learn About Machine Learning." University of California, Davis 51, no 653 (2017): 653-717.

Lipton, Zachary. "The Mythos of Model Interpretability.” ArXiv 1606 (2016). https://arxiv.org/abs/1606.03490

Macey, Gregg. “The Architecture of Ignorance.” Utah Law Review (2013): 1627-1685. https://brooklynworks.brooklaw.edu/faculty/130/. 
Macintosh, Andrew. "Why the Environment Protection and Biodiversity Conservation Act's Referral, Assessment and Approval Process is Failing to Achieve its Environmental Objectives." Environmental and Planning Law Journal 21 , no 4 (2004): 288-311. http://hdl.handle.net/1885/38832.

Markowitz, Kenneth. "Legal Challenges and Market Rewards to the Use and Acceptance of Remote Sensing and Digital Information as Evidence." Duke Environmental Law and Policy Forum 12 (2002): 219-264. https://scholarship.law.duke.edu/delpf/vol12/iss2/1.

McGrath, Chris. "Key Concepts of the Environment Protection and Biodiversity Conservation Act 1999 (Cth)." Environmental and Planning Law Journal 22, no 1 (2005): 20-39.

McMillan, John. "Automated Assistance to Administrative Decision-Making: Launch of the Better Practice Guide." Institute of Public Administration of Australia, Canberra, Australia, 23 April 2007.

Miller, Katie. "The Application of Administrative Law Principles to Technology-Assisted Decision-Making." AIAL Forum 86 (2016): 20-34.

Mosavi, Amir, Pinar Ozturk and Kwok-wing Chau. "Flood Prediction Using Machine Learning Models: Literature Review." Water 10, no 11 (October 2018): 1536-1576. https://doi.org/10.3390/w10111536.

Perry, Melissa. "iDecide: Digital Pathways to Decision.” Law Council of Australia, CPD Immigration Law Conference, 2123 March 2019.

Melissa Perry. "iDecide: Administrative Decision-Making in the Digital World.” Australian Law Journal 91, no 1 (2017): 29-34.

Potts, Jason. "Governing the Innovation Commons.” Journal of Institutional Economics 14, no 6 (2018): 1025-1047. https://doi.org/10.1017/S1744137417000479.

Productivity Commission. Data Availability and Use: Productivity Commission Inquiry Report. (Australian Government, Report No. 82, 31 March 2017).

Provost, Foster, and Tom Fawcett. "Data Science and its Relationship to Big Data and Data-Driven Decision-Making." Big Data 1, no 1 (2013): 51-59. https://doi.org/10.1089/big.2013.1508.

Purdy, Raymond. "Satellites: A New Era for Environmental Compliance?” Journal of European Environmental and Planning Law 3 (2006): 406-13.

Rich, Michael. "Machine Learning, Automated Suspicion Algorithms, and the Fourth Amendment." University of Pennsylvania Law Review 164, no 4 (2016): 871-929. https://scholarship.law.upenn.edu/penn_law_review/vol164/iss4/2

Skitka, Linda, Kathleen Mosier and Mark Burdick. “Accountability and Automation Bias.” International Journal of HumanComputer Studies 52, no 4 (2000): 701-717. https://doi.org/10.1006/ijhc.1999.0349.

Snyder, Emily, Timothy Watkins, Paul Solomon, Eben Thoma, Ronald Williams, Gayle Hagler, David Shelow, David Hindin, Vasu Kilaru and Peter Preuss. "The Changing Paradigm of Air Pollution Monitoring." Environmental Science and Technology 47, no 20 (2013): 11369-11377. https://doi.org/10.1021/es4022602.

Solomon, Jennifer, Michael Gavin and Meredith Gore. "Detecting and Understanding Non-Compliance with Conservation Rules.” Biological Conservation 189 (2015): 1-4. https://doi.org/10.1016/j.biocon.2015.04.028.

Sourdin, Tania. "Judge v Robot? Artificial Intelligence and Judicial Decision-Making." University of New South Wales Law Journal 41, no 4 (2018): 1114-1133. http://www.unswlawjournal.unsw.edu.au/article/judge-v-robot-artificialintelligence-and-judicial-decision-making/.

Spaulding, Norman. "Is Human Judgment Necessary?” In The Oxford Handbook of Ethics of AI, edited by Markus D. Dubber, Frank Pasquale and Sunit Das, 375-402. Oxford: Oxford University Press, 2020.

Squires, Dale, and Niels Vestergaard. "Rethinking the Commons Problem: Technical Change, Knowledge Spillovers, and Social Learning." Journal of Environmental Economic and Management 19 (2018): 1-25. https://doi.org/10.1016/j.jeem.2018.06.011.

Surden, Harry. "Machine Learning and Law.” Washington Law Review 89, no 1 (2014): 87-115. https://digitalcommons.law.uw.edu/wlr/vol89/iss1/5.

Tomaras, Juli. Strengthening the Environment Protection Biodiversity and Conservation Act. (Parliament of Australia, Law and Bills Digest Section, 2010).

https://www.aph.gov.au/About_Parliament/Parliamentary_Departments/Parliamentary_Library/pubs/BriefingBook43p/ep bc.

Van Dijk, Albert, Richard Mount, Philip Gibbons, Michael Vardon and Pep Canadell. "Environmental Reporting and Accounting in Australia: Progress, Prospects and Research Priorities." Science of the Total Environment 473-474 (2014): 338-349. https://doi.org/10.1016/j.scitotenv.2013.12.053.

Vogel, Friedermann, Hanjo Hamann, and Isabelle Gauer. "Computer-Assisted Legal Linguistics: Corpus Analysis as a New Tool for Legal Studies.” Law \& Social Inquiry 43, no 4 (2018): 1340-1383. https://doi.org/10.1111/1si.12305

Waldron, Jeremy. "Vagueness and the Guidance of Action." In Philosophical Foundations of Language in the Law, edited by Andrei Marmor \& Scott Soames, 58-82. Oxford: Oxford University Press, 2011. 
Western Australian Biodiversity Science Institute. Digitally Transforming Environmental Assessment: Leveraging Digital Information to Streamline Environmental Assessment and Approvals. (Report of the Digital Environmental Impact Assessment Working Group, 2020).

Yeung, Karen. “Algorithmic Regulation: A Critical Interrogation.” Regulation and Governance 12, no 4 (2018): $505-523$. https://doi.org/10.1111/rego.12158

Younas, Muhammad. "Research Challenges of Big Data.” Service Oriented Computing and Applications 13 (2019): 105107. https://doi.org/10.1007/s11761-019-00265-X.

Young, Oran and Olav Schram Stokke. "Why is it Hard to Solve Environmental Problems? The Perils of Institutional Reductionism and Institutional Overload." International Environmental Agreements: Politics, Law and Economics 20 (2020): 5-19. https://doi.org/10.1007/s10784-020-09468-6.

Zalnieriute, Monika, Lyria Bennett Moses and George Williams. "The Rule of Law and Automation of Government Decision-Making." Modern Law Review 82, no 3 (2019): 425-455. http://dx.doi.org/10.2139/ssrn.3348831.

Zednik, Carlos. "Solving the Black Box Problem: A Normative Framework for Explainable Artificial Intelligence." Philosophy and Technology (2019): 1-24. https://doi.org/10.1007/s13347-019-00382-7.

Zerilli, John, Alistair Knott, James Maclaurin and Colin Gavaghan. "Transparency in Algorithmic and Human DecisionMaking: Is There a Double Standard?” Philosophy \& Technology 32 (2018): 661-683. https://doi.org/10.1007/s13347018-0330-6.

\section{Primary Legal Material}

Administrative Decisions (Judicial Review) Act 1977 (Cth).

Corporation of the City of Enfield v Development Assessment Commission (2000) 199 CLR 135.

Environment Protection and Biodiversity Conservation Act 1999 (Cth).

Judiciary Act 1903 (Cth).

Minister for the Environment and Heritage v Queensland Conservation Council Inc (2004) 139 FCR 24.

Regulation (EU) 2016/679 of the European Parliament and of the Council of 27 April 2016 on the Protection of Natural Persons with Regard to the Processing of Personal Data and on the Free Movement of such Data, and Repealing Directive 95/46/EC, OJ 2016 L 119/1. 